\title{
First Generation Final Focusing Solenoid For NDCX-I
}

\author{
by \\ P.A. Seidl, W. Waldron \\ Accelerator and Fusion Research Division \\ Ernest Orlando Lawrence Berkeley National Laboratory \\ Berkeley, California 94720
}

Date

November 2011

This work was supported by the Director, Office of Science, Office of Fusion Energy Sciences, of the U.S.

Department of Energy under Contract No. DE-AC02-05CH11231. 
This document was prepared as an account of work sponsored by the United States Government. While this document is believed to contain correct information, neither the United States Government nor any agency thereof, nor The Regents of the University of California, nor any of their employees, makes any warranty, express or implied, or assumes any legal responsibility for the accuracy, completeness, or usefulness of any information, apparatus, product, or process disclosed, or represents that its use would not infringe privately owned rights. Reference herein to any specific commercial product, process, or service by its trade name, trademark, manufacturer, or otherwise, does not necessarily constitute or imply its endorsement, recommendation, or favoring by the United States Government or any agency thereof, or The Regents of the University of California. The views and opinions of authors expressed herein do not necessarily state or reflect those of the United States Government or any agency thereof or The Regents of the University of California.

This work was supported by the Director, Office of Science, Office of Fusion Energy Sciences, of the U.S. Department of Energy under Contract No. DE-AC02-05CH11231. 


\title{
FIRST GENERATION FINAL FOCUSING SOLENOID FOR NDCX-I
}

\author{
Peter A. Seidl and William Waldron, LBNL
}

November 9, 2011

\section{FINAL FOCUSING SOLENOID}

Figure 1(a) shows a sketch of the prototype final focus solenoid (FFS-1G), or $1^{\text {st }}$ generation FFS. In order to limit eddy currents, the solenoid winding consists of Litz wire wound on a non-conductive G-10 tube. For the same reason, the winding pack was inserted into an electrically insulating, but thermally conducting Polypropylene (CoolPoly ${ }^{\circ}$ D1202) housing and potted with highly viscous epoxy (to be able to wick the single strands of the Litz wire). The magnet is forced-air cooled through cooling channels. The magnet was designed for water cooling, but he cooling jacket cracked, and therefore cooling (beyond natural conduction and radiation) was exclusively by forced air. Figure 1(b) shows a field profile taken during initial tests. Table 1 represents summarized main magnet parameters.

Though the design operating point was 8 Tesla, for the majority of running on NDCX-1 it operated up to about 5 Tesla. This was due mostly from limitations of voltage holding at the leads, where discharges at higher pulsed current damaged the leads. Generation 1 was replaced by the $2^{\text {nd }}$ generation solenoid (FFS-2G) about a year later, which has operated reliably up to 8 Tesla, with a better lead design and utilizes water cooling. At this point, FFS-1G was used for plasma source R\&D by LBNL and PPPL. The maximum field for those experiments was reduced to 3 Tesla due to continued difficulty with the leads and because higher field was not essential for those experiments.
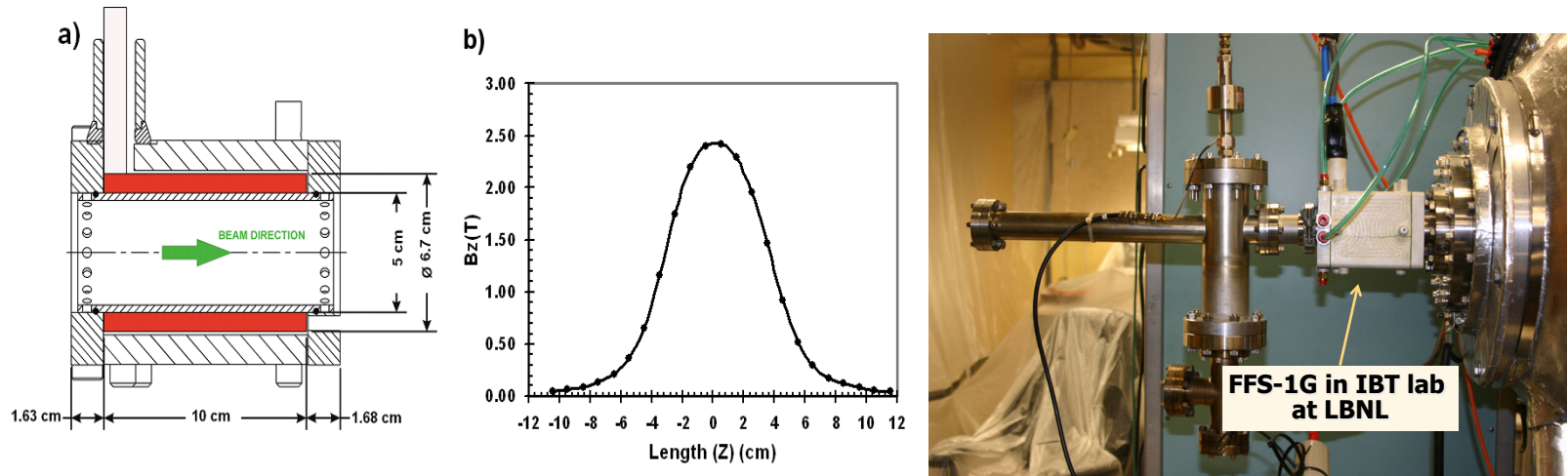

Figure 1. (a) A sketch of final focus solenoid and (b) characteristic magnetic field profile. (c) Photo (A. Anders, LBNL) of the FFS-1G in the IBT lab at LBNL.

TABLE 1. Parameters of the final focus solenoid (FFS).

\begin{tabular}{||l|l||}
\hline PARAMETER & VALUE \\
\hline Maximum solenoid field & $8 \mathrm{~T}$ \\
Effective field length & $10.15 \mathrm{~cm}$ \\
Winding pack id and od & $5.1 \mathrm{~cm}$ and $6.7 \mathrm{~cm}$ \\
Wire specification & 24 strand gauge $20 \mathrm{AWG}$, heavy build \\
& insulation MW80-155 deg., profiled to \\
& $1 \mathrm{~cm} \times 0.16 \mathrm{~cm}$, wrapped in Nomex paper \\
Number of turns & $32(8$ turns $/$ layer) \\
Coil resistance & $7.75 \times 10^{-3} \Omega$, \\
Coil inductance. & $2.80 \times 10^{-5} \mathrm{H}$ \\
Epoxy specification & Ctd-101k \\
Stored energy & $5.9 \mathrm{~kJ}$ \\
Max. Voltage across magnet & $2.4 \mathrm{kV}$ \\
Max. Current & $21.3 \mathrm{kA}$ \\
Pulse length & $784 \mathrm{~ms}$ \\
\hline \hline
\end{tabular}


(Above table from PAC 2007 paper, P.K. Roy et al.) 


\section{PULSER FOR THE FINAL FOCUSING SOLENOID}

The pulser is a SCR-switched capacitor bank which produces a half-sine current waveform. The pulse width is $~ 800$ us and a charge voltage of $3 \mathrm{kV}$ drives $\sim 20 \mathrm{kA}$ through the magnet producing $\sim 8 \mathrm{~T}$ field.

8T Final Focus Solenoid Pulser (3kV, 20kA)

2 series, 3 parallel

(each 150 ohms and 225W)

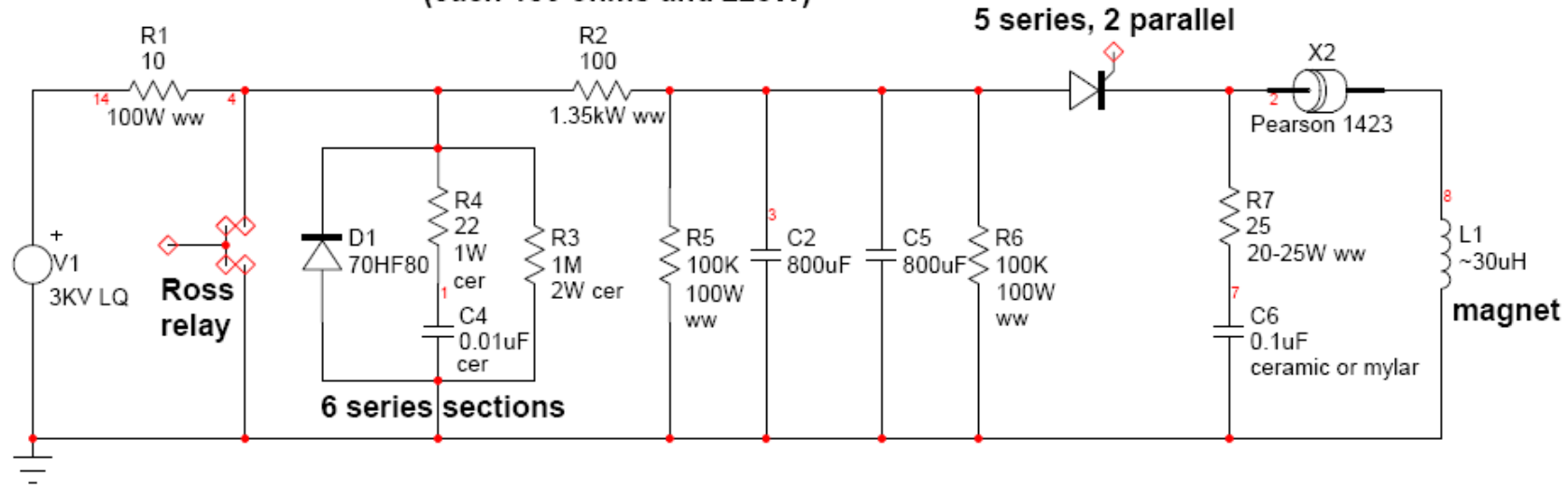

